\title{
Реологические и спектральные свойства водных растворов фенилаланина
}

\author{
Голева Е.А., Васильева В.И., Абрамова Е.О., Сауд Али Мунир, \\ Костылев Д.В., Смагин М.А. \\ ФГБОУ ВО «Воронежский государственный университет», Воронеж
}

Поступила в редакцию 26.03.2018 г.

DOI: https://doi.org/10.17308/sorpchrom.2018.18/499

\begin{abstract}
Исследованы вязкостные и спектральные свойства индивидуальных водных растворов фенилаланина в широком диапазоне концентрации. В области концентраций фенилаланина более $22 \pm 2$ ммоль/дм ${ }^{3}$ обнаружено плато на концентрационной зависимости приведённой вязкости, указывающее на формирование ассоциатов устойчивых конфигураций. Методом фотонной корреляционной спектроскопии установлено, что в этой области концентраций происходит процесс формирования агломератов с гидродинамическими радиусами 90-100 нм и 150-200 нм. Обнаруженное резкое уменьшение величин приведённой вязкости в области концентраций фенилаланина более 0.055 моль/дм ${ }^{3}$ свидетельствует о образовании более плотной трёхмерной структуры.

Ключевые слова: фенилаланин, ассоциативные структуры, вискозиметрия, фотонная корреляционная спектроскопия.
\end{abstract}

\section{Rheological and spectral properties of aqueous solutions of phenylalanine}

\author{
Goleva E.A., Vasil'eva V.I., Abramova E.O., Ali Saud Munir, \\ Kostylev D.V., Smagin M.A. \\ Voronezh State University, Voronezh
}

\begin{abstract}
Viscosity and spectral properties of individual aqueous solutions of phenylalanine in a wide range of concentrations is studied. The structures with hydrodynamic radii of $1-2 \mathrm{~nm}$ and $20-50 \mathrm{~nm}$ in the diluted solutions of phenylalanine with a concentration of less than $22 \pm 2 \mathrm{mmol} / \mathrm{L}$ is revealed. A plateau is observed on the concentration dependence of the reduced viscosity in the region concentrations of phenylalanine of more than $22 \pm 2 \mathrm{mmol} / \mathrm{L}$, indicating the formation of stable configurations associates. It is established that in this region the formation of agglomerates with hydrodynamic radii of $90-100 \mathrm{~nm}$ and $150-200 \mathrm{~nm}$ takes place using the method of photon correlation spectroscopy. The further growth of the reduced viscosity corresponds to an increase in the number of particles in the associative structure. The increase in the concentration of amino acid in the solution leads to a decrease in the content of structures with a hydrodynamic radius of $90-100 \mathrm{~nm}$. There are larger agglomerates with a hydrodynamic radii of $150-200 \mathrm{~nm}$, the maximum content of which corresponds to the extremum of the reduced viscosity. The sharp decrease in the values of the reduced viscosity is indicates the formation of a denser three-dimensional structure in the concentration range of phenylalanine greater than $0.055 \mathrm{~mol} / \mathrm{L}$. The compaction of amino acid associative structure leads to an increase in the content of particles with a hydrodynamic radii of $90-100 \mathrm{~nm}$. A possible scheme of selfassembled structures in the phenylalanine - phenylalanine system is shown.
\end{abstract}

Keywords: phenylalanine, associative structure, viscosimetry, photon correlation spectroscopy. 


\section{Введение}

L-фенилаланин относится к протеиногенной аминокислоте, входящей в состав белков всех известных живых организмов. Фенилаланин является незаменимой аминокислотой, не синтезируется клетками животных и человека, поступает в организм в составе белков пищи. Для сельскохозяйственного и медицинского применения преимущественно пригодны L-формы аминокислот [1-3]. K тому же, фенилаланин известен положительным влиянием на настроение человека, т.к. он стимулирует нервную систему, также стимулирует память. Фенилаланин повышает уровень адреналина, норадреналина, допамина - важных нейротрансмиттеров, необходимых для нормального функционирования нервной системы. Аминокислота используется как неуглеводородный подсластитель в некоторых газированных напитках.

Для разработки высокоэффективных технологий выделения фенилаланина и разделения его смесей в водных растворах необходимы сведения об ионных и молекулярных взаимодействиях в системе аминокислота-вода. Задача данной работы оценка состава и структуры водных растворов фенилаланина в широком диапазоне концентраций методами вискозиметрии и фотонной корреляционной спектроскопии.

\section{Эксперимент}

Фенилаланин ( $\alpha$-амино- $\beta$-фенилпропионовой кислота) - протеиногенная неполярная алкилароматическая аминокислота $\mathrm{NH}_{2} \mathrm{CH}\left(\mathrm{CH}_{2} \mathrm{C}_{6} \mathrm{H}_{5}\right) \mathrm{COOH}$, имеющая в структуре бензольное кольцо, обладающее гидрофобными свойствами. Фенилаланин вступает с водой в реакции протолиза с образованием ионов $\mathrm{H}_{3} \mathrm{O}^{+}$и $\mathrm{OH}^{-}$, катионов и анионов:

$$
\begin{array}{r}
{ }^{+} \mathrm{NH}_{3}-\mathrm{CH}\left(\mathrm{CH}_{2} \mathrm{C}_{6} \mathrm{H}_{5}\right)-\mathrm{COO}^{-}+\mathrm{H}_{2} \mathrm{O} \leftrightarrow{ }^{+} \mathrm{NH}_{3}-\mathrm{CH}\left(\mathrm{CH}_{2} \mathrm{C}_{6} \mathrm{H}_{5}\right)-\mathrm{COOH}+\mathrm{OH}^{-} \\
{ }^{+} \mathrm{NH}_{3}-\mathrm{CH}\left(\mathrm{CH}_{2} \mathrm{C}_{6} \mathrm{H}_{5}\right)-\mathrm{COOH}+\mathrm{H}_{2} \mathrm{O} \leftrightarrow{ }^{+} \mathrm{NH}_{3}-\mathrm{CH}\left(\mathrm{CH}_{2} \mathrm{C}_{6} \mathrm{H}_{5}\right)-\mathrm{COO}^{-}+\mathrm{H}_{3} \mathrm{O}^{+} \\
{ }^{+} \mathrm{NH}_{3}-\mathrm{CH}\left(\mathrm{CH}_{2} \mathrm{C}_{6} \mathrm{H}_{5}\right)-\mathrm{COO}^{-}+\mathrm{H}_{2} \mathrm{O} \leftrightarrow \mathrm{NH}_{2}-\mathrm{CH}\left(\mathrm{CH}_{2} \mathrm{C}_{6} \mathrm{H}_{5}\right)-\mathrm{COO}^{-}+\mathrm{H}_{3} \mathrm{O}^{+} \\
\mathrm{NH}_{2}-\mathrm{CH}\left(\mathrm{CH}_{2} \mathrm{C}_{6} \mathrm{H}_{5}\right)-\mathrm{COO}^{-}+\mathrm{H}_{2} \mathrm{O} \leftrightarrow{ }^{+} \mathrm{NH}_{3}-\mathrm{CH}\left(\mathrm{CH}_{2} \mathrm{C}_{6} \mathrm{H}_{5}\right)-\mathrm{COO}^{-}+\mathrm{OH}^{-}
\end{array}
$$

Значения констант химических равновесий $K_{1}$ и $K_{2}$ реакций (1) и (2) при $25^{\circ} \mathrm{C}$ равны соответственно $10^{-2.59}$ и $10^{-9.24}[4,5]$.

Равновесные концентрации катионов $\mathrm{Phe}^{+}$и анионов $\mathrm{Phe}^{-}$фенилаланина в растворе определяются соотношениями:

$$
\left[\mathrm{Phe}^{+}\right]=\frac{\left[\mathrm{H}_{3} \mathrm{O}^{+}\right] \cdot\left[\mathrm{Phe}^{ \pm}\right]}{K_{1}} \quad\left[\mathrm{Phe}^{+}\right]=\frac{\mathrm{K}_{2} \cdot\left[\mathrm{Phe}^{ \pm}\right]}{\left[\mathrm{H}_{3} \mathrm{O}^{+}\right]},
$$

где $\mathrm{Phe}^{ \pm}-$концентрация биполярных ионов, близкая к исходной концентрации аминокислоты.

Для концентрации раствора фенилаланина 0.018 моль/дм ${ }^{3}$ при $\mathrm{pH}=5.60$ концентрации катионов и анионов равны $2.38 \cdot 10^{-5}$ и $5.72 \cdot 10^{-6}$ моль/дм ${ }^{3}$, что соответственно составляет 0.09 и $0.02 \%$.

В исследуемых водных растворах фенилаланин находился преимущественно в виде биполярных ионов, так как $\mathrm{pH}$ растворов имел значения $5.60 \pm 0.05$, близкие к величине изоэлектрической точки фенилаланина $\mathrm{pI}=\left(\mathrm{pK}_{1}+\mathrm{pK}_{2}\right) / 2=5.91$ [5]. Выбранный диапазон концентраций модельных растворов фенилаланина, приготовленных из реактивов классификации «ч.д.а.», составлял 0.0010- 
0.1500 моль/дм ${ }^{3}$ максимальное значение концентрации ограничено растворимостью аминокислоты.

Для оценки динамической вязкости водных растворов фенилаланина использовали капиллярный вискозиметр с висячим уровнем Уббелоде при диаметре капилляра 0.37 мм [6]. При определении вязкости растворов аминокислоты измеряли время истечения объемов растворителя $\mathrm{t}_{0}$ и исследуемого водного раствора $t$ через капилляр вискозиметра при заданной постоянной температуре $20^{\circ} \mathrm{C}$.

Приведенную вязкость $\eta_{n p}$ находили как отношение удельной вязкости раствора к его концентрации С (г/дм $\left.{ }^{3}\right)$ :

$$
\eta_{n p}=\frac{\eta_{y d}}{C}
$$

где удельная вязкость $\eta_{y д}$ есть отношение разности времен истечения раствора $\mathrm{t}$ и растворителя $\mathrm{t}_{0}$ к времени истечения растворителя:

$$
\eta_{y d}=\frac{t-t_{0}}{t_{0}}=\eta_{\text {om }}-1
$$

Концентрационные зависимости приведенной вязкости $\eta_{n p}$ водных растворов аминокислоты использовались для анализа возможности образования ассоциативных структур.

Размер частиц в водных растворах фенилаланина измеряли методом динамического рассеяния света (фотонная корреляционная спектроскопия), основанного на анализе временной автокорреляционной функции интенсивности рассеянного света $[7,8]$. Метод фотонной корреляционной спектроскопии позволяет определить коэффициент диффузии дисперсных частиц в жидкости путем анализа характерного времени флуктуаций интенсивности рассеянного света. Из коэффициента диффузии рассчитывается эффективный гидродинамический радиус частиц по уравнению Эйнштейна-Стокса.

Прибор Photocor-Complex (Россия) с источником света - гелий-неоновым лазером ( $\lambda=633 \mathrm{нм)} \mathrm{мощностью} 10$ мВт позволяет проводить измерения размера частиц в диапазоне от 1нм до 10 мкм с ошибкой менее $10 \%$. Измерения распределения частиц по размерам в растворах фенилаланина проводили через 1 ч после их приготовления. Расшифровка полученных данных осуществлялась с учетом того, что информация о наличии частиц с радиусом более $10^{4}$ нм является не корректной и обусловлена высокой чувствительностью установки к разного рода частицам, загрязняющим систему.

\section{Обсуждение результатов}

На рис. 1 представлена концентрационная зависимость реологических свойств водных растворов фенилаланина.

Если бы в водном растворе фенилаланина не происходили процессы межмолекулярных взаимодействий и структурирования, то величина приведенной вязкости сохраняла постоянное значение при всех концентрациях [9]. Однако, в области разбавленных растворов при $\mathrm{C}(\mathrm{Phe}) \geq 0.018$ моль/дм ${ }^{3}$ наблюдается линейная зависимость приведенной вязкости от концентрации аминокислоты, что свидетельствует о структурной перестройке и начале процесса образования ассоциатов фенилаланина.

Способность молекул фенилаланина к самоассоциации следует исходя из его химической структуры. Наличие двух функциональных групп (карбоксильной группы и аминогруппы) обеспечивает образование межмолекулярной водородной связи. В разбавленных водных растворах фенилаланина возможно образование димеров за 
счет водородной связи недиссоциированных карбоксильных групп и отличающихся по стабильности структур Phe $\left(\mathrm{H}_{2} \mathrm{O}\right)_{\mathrm{n}}$ с различной координацией молекул воды [10, 11]. Водородные связи могут образовывать пространственную сетку, которая непрерывно перестраивается под действием тепловых флуктуаций.

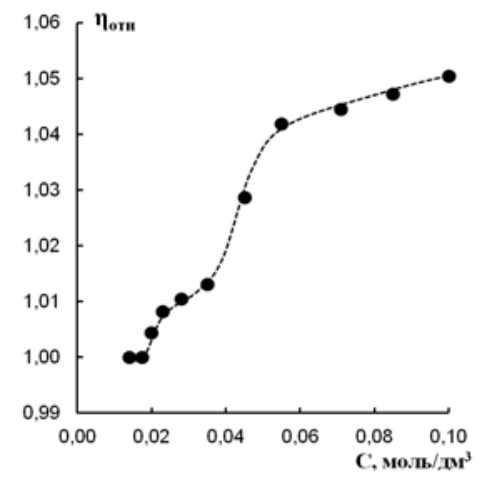

a

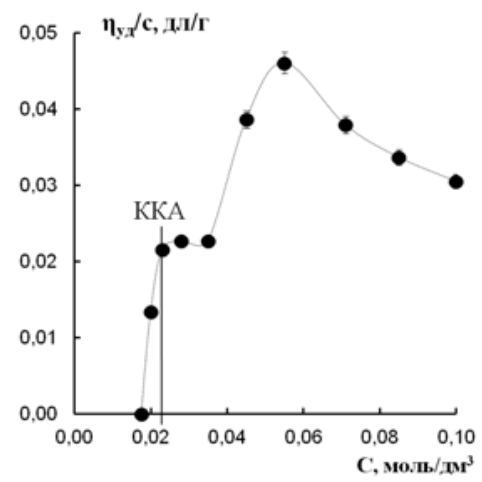

б

Рис. 1. Концентрационная зависимость относительной (а) и приведенной (б) вязкостей в растворах фенилаланина.

Известна способность фенилаланина к мицеллообразованию при ККМ= 0.022 моль/дм ${ }^{3}$ [12-14] за счет образования водородных связей между аминокарбоксильными группировками и молекулами воды с ориентацией гидрофобных радикалов аминокислоты наружу [15]. В области концентраций 0.022-0.035 моль/дм ${ }^{3}$ на концентрационной зависимости приведенной вязкости наблюдается плато, указывающее на формирование ассоциатов устойчивых конфигураций. Дальнейшее увеличение приведенной вязкости растворов соответствует концентрационной области роста количества частиц в ассоциате. После достижения максимального значения при концентрации аминокислоты 0.055 моль/дм ${ }^{3}$ наблюдается резкое уменьшение величины приведенной вязкости, что свидетельствует о образовании более плотной трехмерной структуры аминокислотных ассоциатов.

Гистограммы, характеризующие распределение ассоциатов фенилаланина по гидродинамическим радиусам в водных растворах разной концентрации, приведены на рис. 2.

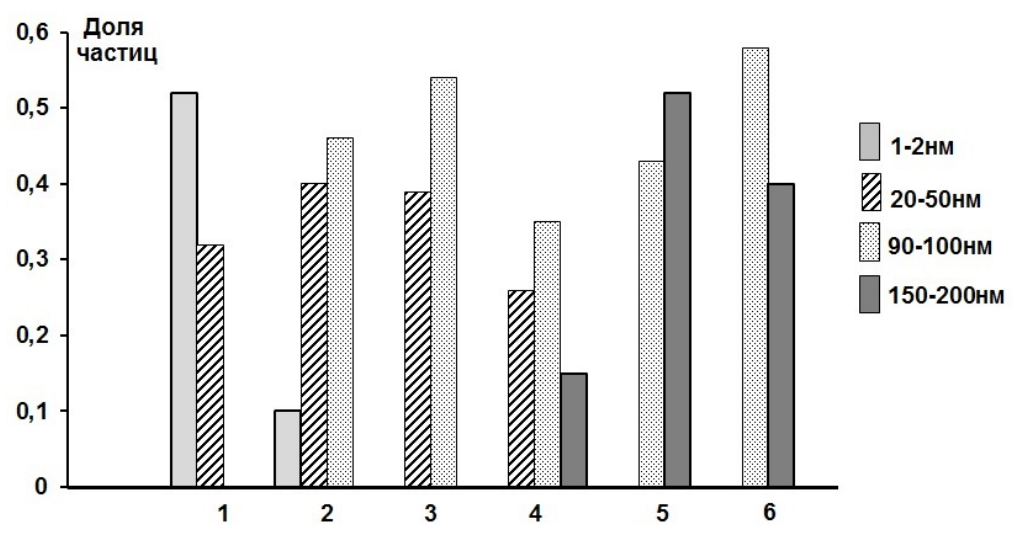

Рис. 2. Гистограмма распределения ассоциатов фенилаланина по гидродинамическим радиусам в водных растворах с концентрацией 0.010 (1), 0.020 (2), 0.030 (3), 0.045 (4), 0.060 (5) и 0.070 (6) моль/дм ${ }^{3}$.

В разбавленных растворах с концентрацией меньше ККА выявлено существование структур с радиусами в диапазонах 1-2 нм и 20-50 нм. Области плато концентрационной зависимости приведенной вязкости соответствуют ассоциаты аминокис- 
лоты с гидродинамическими радиусами 20-50 нм и 90-100 нм, а частицы с $r=1-2$ нм практически исчезают. Дальнейшее увеличение концентрации фенилаланина в растворе приводит к уменьшению содержания агломератов с радиусом 90-100 нм, а также к появлению более крупных с $r=150-200 н$, максимальное содержание которых соответствует области экстремума приведенной вязкости. Уплотнение аминокислотных ассоциатов сопровождается увеличением содержания частиц с гидродинамическим радиусом 90-100 нм. Причиной этого могут являться межплоскостные $\pi-\pi$ взаимодействия (стэкинг-взаимодействия) ароматических колец фенилаланина $[16,17]$. Возможная схема самоорганизующихся структур в растворе фенилаланина представлена на рис. 3.

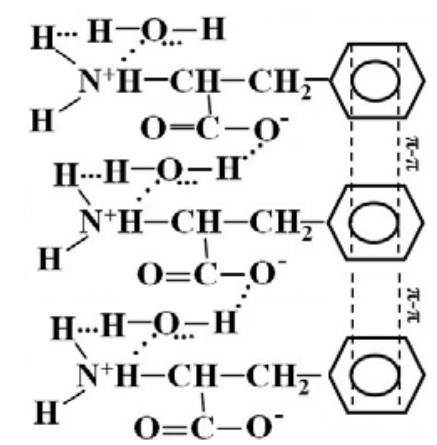

Рис. 3. Возможная схема образования самоорганизирующихся ассоциативных структур в растворе фенилаланина.

\section{Заключение}

На основании полученных результатов вязкостных и спектральных свойств индивидуальных водных растворов фенилаланина доказано образование ассоциативных структур. Определены концентрационные границы существования и распределение ассоциатов по размерам в растворах фенилаланина.

Результаты исследований состава и структуры водных растворов фенилаланина позволяют оптимизировать процессы сорбции и разделения. Степень ассоциации аминокислоты определяет транспортные характеристики фенилаланина при очистке промывных вод микробиологического синтеза. Применение разбавленных растворов фенилаланина концентрации менее 20 ммоль/дм ${ }^{3}$ позволит более эффективно выделять аминокислоту.

\section{Работа выполнена при финансовой поддержке РФФИ (проект № 18-08-01260).}

\section{Список литературы}

1. Быков В.А., Крылов И.А., Манаков М.Н. и др. Микробиологическое производство биологически активных веществ и препаратов. М. Высшая школа. 1987. 143 с.

2. Ленинджер А. Основы биохимии. М. Мир. 1985.368 с.

3. Якубке Х.-Д., Ешкайт Х. Аминокислоты. Пептиды. Белки. М. Мир. 1985. 82 с.

4. Майстер А. Биохимия аминокислот. М. Химия. $1961.630 \mathrm{c.}$
5. Уайт А., Хендлер Ф., Смит Э. и др. Основы биохимии. М. Мир. 1981.535 с.

6. ГОСТ Р 53708-2009. Нефтепродукты. Жидкости прозрачные и непрозрачные. Определение кинематической вязкости и расчет динамической вязкости. Москва, Стандартинформа. 2010. 20 c.

7. Pecora B.J. Dynamic light scattering: Applications of photon correlation spectroscopy. New York and London, Plenum Press. 1985. $420 \mathrm{p}$. 
8. Анализаторы размеров наночастиц, дзета-потенциала и молекулярной массы Электронный pecypc. URL: http://www.photocor.ru/

9. Воюцкий С.С. Курс коллоидной химии. М. Химия. 1976. 512 с.

10.Котова Д.Л., Бейлина Д.С., Крысанова Т.А. // Жур. физ. химии. 2004. Т. 78. № 8. С. 1406-1409.

11.Селеменев В.Ф., Хохлов В.Ю., Бобрешова О.В. и др. Физико-химические основы сорбционных и мембранных методов выделения и разделения аминокислот. М. Стелайт. 2002. 299 с.

12.Хохлова О.Н. // Жур. физ. химии. 2010. T. 84. № 5. C. 956-959.

13.Карлашова Т.С., Трунаева Е.С., Хохлова О.Н. и др. // Сорбиионные и хроматографи-

\section{References}

1. Bykov V.A., Krylov I.A., Manakov M.N. et al., Microbiological production of biologically active substances and preparations, M., High School Publ., 1987, 143 p.

2. Lenindzher A. Fundamentals of Biochemistry. M., Mir Publ., 1985, 368 p.

3. Jakubke H.-D., Eshkajt H. Amino acids. Peptides. Proteins. Moscow, Mir Publ., 1985, 82 p.

4. Majster A. Biochemistry of amino acids. Moscow, Chemistry Publ., 1961, 630 p.

5. Uajt A., Hendler F., Smit Je. et al. Fundamentals of Biochemistry. M., Mir Publ., 1981, $535 \mathrm{p}$.

6. GOST R 53708-2009, Petroleum products. Liquids transparent and opaque. Determination of kinematic viscosity and calculation of dynamic viscosity, Moscow, Standartinform, 2010. $20 \mathrm{p}$.

7. Pecora B.J. Dynamic light scattering: Applications of photon correlation spectroscopy. New York and London, Plenum Press Publ., 1985. $420 \mathrm{p}$.

8. URL: http://www.photocor.ru/

9. Vojuckij S.S., Kurs kolloidnoy khimii, M., Chemistry Publ., 1976, 512 p.

10. Kotova D.L., Beilina D.S., Krysanova T.A., Rus. J. of Phys. Chem. A, 2004, Vol. 78, No 8. pp. 1230-1233.

Голева Елена Алексеевна - к.Х.н., ведущий инженер кафедры аналитической химии химического факультета, Воронежский государственный университет, Воронеж ческие процессы. 2014. Т. 14. № 4. С. 648653.

14.Голева Е.А., Васильева В.И., Селеменев В.Ф. и др. // Сорбиионные и хроматографические проиессы. 2016. Т. 16. №. 5. С. 640652.

15.Трунаева Е.С., Хохлова О.Н., Хохлов В.Ю. // Журнал структурной химии. 2015. Т. 56. № $6 . \quad$ C. $1111-1115$. DOI: $10.15372 / \mathrm{JSC} 20150605$

16.Абросимов В.К., Агафонов А.В., Чумакова Р.В. Биологически активные вещества в растворах: структура, термодинамика, реакционная способность. М. Наука. 2001. 397 с.

17.Тиноко И., Зауэр К., Вэнг Дж. и др. Физическая химия. Принципы и применение в биологических науках. М. Техносфера. 2005. $744 \mathrm{c}$.

11. Selemenev V.F., Khokhlov V.Yu., Bobreshova O.V. et al., Fiziko-himicheskie osnovy sorbcionnyh i membrannyh metodov vydeleniya i razdeleniya aminokislot, M., Stelait Publ., 2002, 299 p.

12. Khokhlova O.N., J. of Phys. Chem. A, 2010, Vol. 84, No 5, pp. 956-959.

13. Karlashova T.S., Trunaeva E.S., Khokhlova O.N. et al., Sorbtsionnye $i$ khromatograficheskie protsessy, 2014, Vol. 14, No 4, pp. 648-653.

14. Goleva E.A., Vasil'eva V.I., Selemenev V.F. el al., Sorbtsionnye i khromatograficheskie protsessy, 2016, Vol. 16, No 5, pp. 640-652.

15. Trunaeva E.S., Khokhlova O.N., Khokhlov V.Yu., J. of Structural Chemistry, 2015, Vol. 56, No 6, pp. 1058-1062. DOI: $10.1134 / \mathrm{S} 0022476615060050$

16. Abrosimov V.K., Agafonov A.V., Chumakova R.V. Biologicheski aktivnye veshchestva $\mathrm{v}$ rastvorah: struktura, termodinamika, reakcionnaya sposobnost', M., Nauka Publ., 2001, 397p. 17. Tinoko I., Zaujer K., Vjeng Dzh. et al. Fizicheskaya himiya. Principy i primenenie v biologicheskih naukah. M., Tehnosfera Publ., 2005, $744 \mathrm{p}$.

Goleva Elena A. - PhD (Chem.), leading engineer of the Analytical Chemistry Department, Voronezh State University, Voronezh, e-mail: vorobjeva_ea@mail.ru 
Васильева Вера Ивановна - д.Х.Н., профессор кафедры аналитической химии химического факультета, Воронежский государственный университет, Воронеж

Абрамова Екатерина Олеговна - студентка кафедры аналитической химии химического факультета, Воронежский государственный университет, Воронеж

Сауд Али Мунир - аспирант кафедры аналитической химии химического факультета, Воронежский государственный университет, Воронеж

Костылев Денис Викторович - студент кафедры аналитической химии химического факультета, Воронежский государственный университет, Воронеж

Смагин Михаил Алексеевич - студент кафедры аналитической химии химического факультета, Воронежский государственный университет, Воронеж
Vasil'eva Vera I. - Dr. Sci. (Chem.), the professor of the Analytical Chemistry Department, Voronezh State University, Voronezh, e-mail: viv155@mail.ru

Abramova Ekaterina O. - the student of the Analytical Chemistry Department, Voronezh State University, Voronezh

Ali Saud Munir - the postgraduate student of the Analytical Chemistry Department, Voronezh State University, Voronezh

Kostylev Dmitriy V. - the student of the Analytical Chemistry Department, Voronezh State University, Voronezh

Smagin Mikhail A. - the student of the Analytical Chemistry Department, Voronezh State University, Voronezh 